\title{
Psychological Effects and Associated Factors of COVID-19 in a Mexican Sample
}

\author{
Nadia Yanet Cortés-Álvarez, PhD; Regino Piñeiro-Lamas, PhD; César Rubén Vuelvas-Olmos, MSc
}

\section{ABSTRACT}

Objectives: The coronavirus disease 2019 (COVID 19) is a new viral zoonosis of global concern that could cause psychological sequelae. We examined the levels of psychological distress, anxiety, depression, and stress during the COVID-19 outbreak in a Mexican sample.

Methods: An online survey was applied that collected information on demographic and financial status data, physical status, contact history, knowledge, concerns, and precautionary measures concerning COVID-19. Impact of Event Scale-Revised and Depression, Anxiety, and Stress Scale were included.

Results: A total of $50.3 \%$ of respondents rated psychological distress as moderate-severe; $15.7 \%$ reported moderate-severe depressive symptoms; $22.6 \%$ reported moderate-severe anxiety symptoms; and $19.8 \%$ reported moderate-severe stress levels. Female gender, older age, divorced status, lack of confidence related to security of the test, lower satisfaction of health information concerning COVID-19, history of direct or indirect contact with a COVID-19 confirmed case, live with just 1 other person, and spent $>9 \mathrm{~h} / \mathrm{d}$ at home were associated with greater psychological distress and/or higher levels of stress, anxiety, and depression. By contrast, precautionary measures, such as hand hygiene and wearing masks, were associated with lower levels of psychological distress, depression, anxiety, and stress.

Conclusions: COVID-19 outbreak results in considerable psychological effects among the Mexican sample.

Key Words: anxiety, depression, COVID-19, epidemic, psychological distress, stress


oronavirus disease 2019 (COVID-19) originated in the city of Wuhan, China, on December 31, 2019. Since its discovery, a rapid community, regional, and international spread has occurred with exponential growth in cases and deaths. ${ }^{1}$ The COVID-19 outbreak was confirmed to have reached Mexico on February 28, and on March 30, the Mexico government declared a national health emergency. ${ }^{2}$ In the face of a health crisis, not seen in several years, response efforts by the government in coordination with the Secretaría de Salud (Ministry of Health) of Mexico have been swift, implementing a series of preventions, actions, and control infections in the country, including extension of school vacation period, home office, restriction of massive events, suspension of "nonessential activities" in all economic sectors, and the recommendation of home confinement for the general population. ${ }^{3}$ Some negative implications that COVID-19 has had in Mexico include the generation of panic buying and shoplifting, which in turn has led to the eventual shortage of antibacterial hand gel and face masks, ${ }^{4}$ a fall in the price of fuel, ${ }^{5}$ and the temporary or definitive closure of companies. ${ }^{6}$ In fact, in the past month, 346,878 formal jobs were lost in Mexico between March 13 and April 6. ${ }^{7}$
COVID-19 not only threatens people's physical health, but also could affect people's mental health, as many theories indicate. For example, according to Behavioral Immune System theory, ${ }^{8}$ people show emotions, such as aversion and anxiety, for selfprotection..$^{9,10}$ Moreover, stress theory ${ }^{11}$ and perceived risk theory ${ }^{12}$ mention that public health emergencies trigger negative emotions, which may reduce the immune function of people and destroy the balance of their normal physiological mechanisms. ${ }^{13}$ In support, previous studies have shown the immediate psychological sequelae of a pandemic, as occurred with severe acute respiratory syndrome (SARS) and H1N1, include stress, poor sleep, depressed mood, weepiness, nightmares, and poor concentration. ${ }^{14}$ Furthermore, it has also been shown that people experience fear of falling sick or dying themselves, feelings of helplessness, irrational nervousness, loneliness, and stigma. . $^{15,16}$

Also, it has been identified that certain groups are more vulnerable to high psychological distress during a pandemic. Taylor et al. reported that, during an outbreak of equine influenza, younger people, those with no formal educational qualifications, and those with financial dependence on an industry facing a crisis 
are significantly predisposed to high psychological distress. Finally, the authors also identified that those with 1 child had a 1.2 times higher risk of high psychological distress than those with no children. ${ }^{17}$ For their part, during pandemic influenza, Jacobs et al. found that individuals with poor self-rated health reported greater risk perception and concern for self and others than individuals with good self-rated health. ${ }^{18}$ Finally, di Giuseppe et al. reported that people with lower socioeconomic status and lower education showed significantly higher risk perception during avian influenza. ${ }^{19}$

Therefore, it is essential to understand the potential psychological effects caused by COVID-19 in a timely manner. Based on our understanding, there is no information on the psychological distress and mental health of Mexican populations concerning COVID-19. This is especially pertinent with the uncertainty surrounding an outbreak of such unparalleled magnitude in our country. Therefore, this study aims to examine the levels of psychological distress (anxiety, depression, and stress) and identify risk factors contributing to worse outcome during the COVID-19 outbreak in a Mexican sample. We hypothesized that most of the respondents will show severe psychological distress and moderate depressive, anxiety, and stress levels caused by COVID-19. In addition, age, gender, and financial status will be factors contributing to worse outcomes.

\section{METHODS}

\section{Participants and Procedure}

We carried out a cross-sectional study design. As the Mexican Government recommended home confinement for the general population, an anonymous online questionnaire in Spanish was applied through an online survey platform ("Google Forms", Google Inc., CA). The online survey was first disseminated to university students, and they were encouraged to pass it on to others. A snowball sampling strategy, focused on recruiting the general public living in the whole country during the epidemic of COVID-19, was used. This study was conducted in compliance with the Norma Oficial Mexicana012-SSA3-2012, Declaration of Helsinki and the Ethics Committee of Universidad José Martí (Approval number 2020-3). Informed consent was obtained from all participants included in the study. Data collection was carried out from March 30 to April 5, that is, immediately after a national health emergency was declared in Mexico.

\section{Survey}

We reviewed a previous survey on the psychological distress of COVID-19 performed in China. ${ }^{20}$ In addition, we included questions related to employment status during the COVID19 outbreak. The questionnaire consisted of 70 items (about the past 14 days) that covered 8 areas: demographic data, financial status, physical health, contact history, knowledge and concerns, precautionary measures, psychological distress, and mental health status (more details see Appendix 1, online only).

The psychological distress was examined using the Impact of Event Scale-Revised (IES-R). The IES-R is a selfadministered questionnaire that has been applied to the Mexican sample for determining the extent of psychological distress after traumatic and/or stressing experiences. ${ }^{21}$ In addition, it has been used in a recent study for determining the extent of psychological distress during COVID-19.20 The questionnaire was composed of 22 multiple choice items. The responses are rated on a 5-point scale ranging from 0 ("not at all") to 4 ("completely agree"). The total IES-R score was used to perform the inferential statistics, whereas for descriptive statistics, the total IES-R score was divided into normal (0-23), mild (24-32), moderate (33-36), and severe psychological distress $(>37) .{ }^{22}$

The mental health status was assessed by the Depression, Anxiety, and Stress Scale (DASS-21). This scale has been used previously in research related to outbreaks as $\mathrm{H} 1 \mathrm{~N} 1,{ }^{23}$ SARS, ${ }^{24}$ and recently, in COVID-19 outbreak in china (20). In addition, DASS-21 scale is considered as a reliable and valid measure in assessing mental health in the Mexican population. ${ }^{25}$ This 21 -item questionnaire aims to measure depression, anxiety, and stress subscales. Response options are on a 4 -point scale $(0=$ did not apply to me at all and $3=$ applied to me most of the time). Questions 3, 5, $10,13,16,17$, and 21 formed the depression subscale. The total depression subscale score was divided into normal (0-9), mild depression (10-12), moderate depression (13-20), severe depression (21-27), and extremely severe depression (28-42). Questions 2, 4, 7, 9, 15, 19, and 20 formed the anxiety subscale. The total anxiety subscale score was divided into normal (0-6), mild anxiety (7-9), moderate anxiety (10-14), severe anxiety (15-19), and extremely severe anxiety (20-42). Questions 1, 6, 8, 11, 12, 14, and 18 formed the stress subscale. The total stress subscale score was divided into normal (0-10), mild stress (11-18), moderate stress (19-26), severe stress (27-34), and extremely severe stress (35-42).20

\section{Statistical Analysis}

Descriptive statistics was used for categorical variables, such as sociodemographic characteristics, financial status, physical status, contact history, knowledge and concerns, and precautionary measures. Univariate generalized linear with a main effects model (linear regression) was used to measure the associations between sociodemographic characteristics, financial status, physical status, contact history, knowledge and concerns, and precautionary measures with regard the total IES-R score and DASS-21 subscales scores. Associations are presented using beta coefficients, confidence intervals, and P-values. The significance level was set at 0.05 . Analyses were performed in IBM SPSS Statistics (version 25.0). 
TABLE 1

\begin{tabular}{|c|c|c|}
\hline \multicolumn{3}{|c|}{ Sample Characteristics } \\
\hline Parameter & $N$ & Percent \\
\hline \multicolumn{3}{|l|}{ Gender } \\
\hline Male & 418 & 37.9 \\
\hline Female & 686 & 62.1 \\
\hline \multicolumn{3}{|l|}{ Age (years) } \\
\hline 18 to 28 & 759 & 68.7 \\
\hline 29 to 39 & 199 & 18.0 \\
\hline 40 to 50 & 89 & 8.1 \\
\hline 51 a 61 & 47 & 4.3 \\
\hline$>62$ & 10 & 0.9 \\
\hline \multicolumn{3}{|l|}{ Level of education } \\
\hline Primary school & 4 & 0.4 \\
\hline Secondary school & 41 & 3.8 \\
\hline High school & 263 & 24.5 \\
\hline College & 672 & 62.6 \\
\hline Specialty & 29 & 2.7 \\
\hline Master & 54 & 5.0 \\
\hline Doctorate & 10 & 0.9 \\
\hline \multicolumn{3}{|l|}{ Marital status } \\
\hline Single & 785 & 71.1 \\
\hline Common-law marriage & 65 & 5.9 \\
\hline Married & 210 & 19.0 \\
\hline Divorced & 35 & 3.2 \\
\hline Widowed & 9 & 0.8 \\
\hline \multicolumn{3}{|l|}{ Parental status } \\
\hline With children & 292 & 26.4 \\
\hline Not children & 812 & 73.6 \\
\hline \multicolumn{3}{|l|}{ Household size } \\
\hline 1 & 85 & 7.7 \\
\hline 2 & 181 & 16.4 \\
\hline 3 & 268 & 24.3 \\
\hline$>3$ & 570 & 51.6 \\
\hline
\end{tabular}

Abbreviations: $\beta$, beta coefficient; $\mathrm{CI}$, confidence interval; $N=$ sample size

\section{RESULTS}

A total of 1105 persons from 32 states in Mexico were included in the study (more details see Appendix 2, online only) from a convenience sample of 1109 respondents (response rate $=99.63$ ). Sociodemographic characteristics of the final sample of respondents are presented in Table 1 . The majority of respondents were female $(62.1 \%)$, aged 18 to 28 y $(68.7 \%)$ $(\mathrm{SD}=10.46)$, single $(71.1 \%)$, with a household size of $>3$ people $(51.6 \%)$, without children $(67.4 \%)$, and well educated ( $71.2 \% \geq$ college degree).

\section{Psychological Distress and Mental Health}

The psychological distress of COVID-19 outbreak, measured using the IES-R scale, revealed a sample mean score of $26.07(\mathrm{SD}=19.33)$. Of the total respondents, 33\% reported minimal psychological distress, $16.7 \%$ rated mild psychological distress, and $50.3 \%$ reported moderate or severe psychological distress. About the DASS 21 scale, who assessed mental health, revealed a sample mean score of $13.38(\mathrm{SD}=4.51)$. Results showed that $15.7 \%$ reported moderate to severe depressive symptoms, $22.6 \%$ of respondents reported moderate to severe anxiety symptoms, and $19.8 \%$ reported moderate to severe stress levels.

\section{Sociodemographic Characteristics, Psychological Distress, and Mental Health}

The results of the associations of psychological distress and mental health according to the sociodemographic variables are shown in Table 2 .

\section{Gender}

Female gender was significantly associated with higher scores on the IES-R scale $(B=7.273 ; 95 \%$ confidence interval $[\mathrm{CI}]=1.1881$ to 9.960$)$. In the DASS-21 subscales, women were also the ones who showed higher scores in depression $(\mathrm{B}=1.375 ; 95 \% \mathrm{CI}=0.3208$ to 2.004$)$, anxiety $(\mathrm{B}=1.361$; $95 \% \mathrm{CI}=0.3266$ to 1.962$)$, and stress $(\mathrm{B}=1.682 ; 95 \%$ $\mathrm{CI}=0.3542$ to 2.376$)$.

\section{Age}

Participants of 40-50 y were significantly associated with higher scores on IES-R scale $(B=14.418 ; 95 \% \mathrm{CI}=2.018$ to 26.818). About DASS-21 assessment, participants of 18 to $28 \mathrm{y}$ were significantly associated with higher scores in anxiety ( $B=3.607 ; 95 \% \mathrm{CI}=0.404$ to 6.810$)$ and stress subscale $(B=5.236 ; 95 \% C I=1.552$ to 8.920$)$. In addition, respondents of 29 to 39 y $(B=4.481 ; 95 \% \mathrm{CI}=0.862$ to $8.100)$ and 40 to 50 y $(B=3.898 ; 95 \% \mathrm{CI}=0.191$ to 7.604$)$ showed a significantly association with higher scores in stress subscale.

\section{Marital Status}

Divorced status was significantly associated with higher scores in DASS-21 subscale depression $(B=0.630 ; 95 \% \mathrm{CI}=0.168$ to 1.093$)$. Marital status was not associated with IES-R score.

\section{Household Size}

Household size of 2 persons was significantly associated with higher scores in DASS-21 subscale anxiety $(B=0.852 ; 95 \%$ $\mathrm{CI}=0.008$ to 1.696$)$ and higher scores on IES-R scale $(\mathrm{B}=3.722 ; 95 \% \mathrm{CI}=0.499$ to 0.6 .944$)$.

\section{Financial Status, Psychological Distress, and Mental Health}

Employed (52.4\%) and student (38.8\%) status were more frequent for respondents. The most common monthly income was $0-4000 \mathrm{MXN}$. Most of the employees did not show risk for job loss $(56.6 \%)$, reduction in working days $(58.8 \%)$, or reduction in monthly income $(52.0 \%)$. The financial status was not associated with DASS-21 and IES-R subscale scores (see Table 3). 
TABLE 2

Association Between Demographic Characteristics, Psychological Impact, and Mental Health Status During the COVID-19 Outbreak

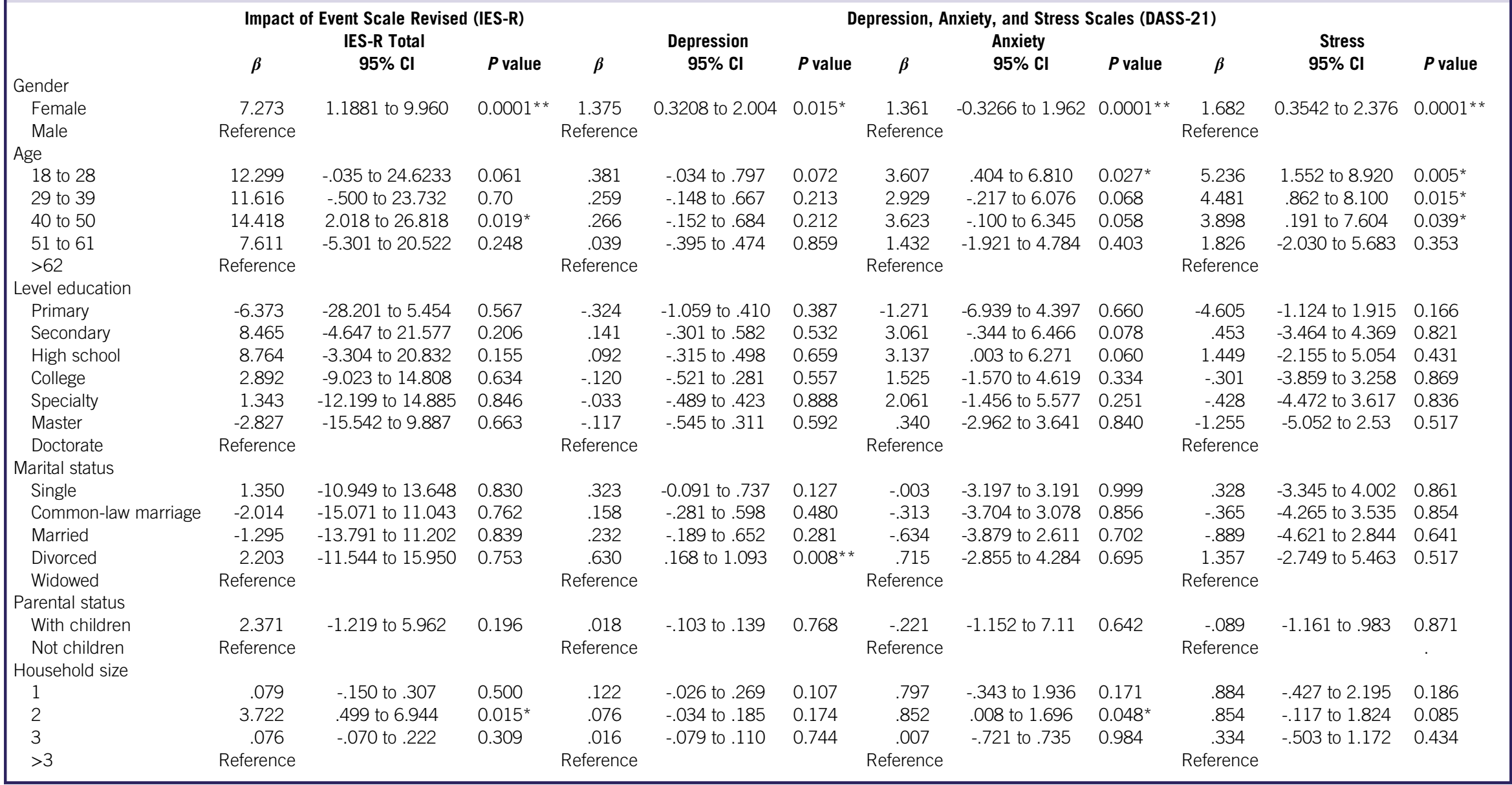

Abbreviations: $\beta$, beta coefficient: $\mathrm{CI}$, confidence interval.

$* P<0.05$

** $P<0.001$ 
TABLE 3

Association Between Financial Status, Psychological Impact, as Well as Adverse Mental Health Status During the Epidemic

\begin{tabular}{|c|c|c|c|c|c|c|c|c|c|c|c|c|}
\hline & \multirow{2}{*}{\multicolumn{3}{|c|}{ Impact of Event Scale Revised (IES-R) }} & \multicolumn{9}{|c|}{ Depression, Anxiety and Stress Scales (DASS-21) } \\
\hline & & & & & Depression & & & Anxiety & & & Stress & \\
\hline & $\beta$ & $95 \% \mathrm{Cl}$ & $P$ value & $\beta$ & $95 \% \mathrm{Cl}$ & $P$ value & $\beta$ & $95 \% \mathrm{Cl}$ & $P$ value & $\beta$ & $95 \% \mathrm{Cl}$ & $P$ value \\
\hline \multicolumn{13}{|c|}{ Employment status } \\
\hline Student & 2.944 & -27.964 to 33.852 & 0.852 & -3.047 & -11.280 to 5.187 & 0.468 & -2.069 & -9.983 to 5.845 & 0.608 & .314 & -9.002 to 9.629 & 0.947 \\
\hline Employee & -3.345 & -19.961 to 13.270 & 0.693 & -2.024 & -6.451 to 2.402 & 0.370 & -1.343 & -5.597 to 2.912 & 0.536 & -.971 & -5.979 to 4.037 & 0.704 \\
\hline Housewife & -2.964 & -19.542 to 13.614 & 0.726 & -2.352 & -6.768 to 2.065 & 0.297 & -1.351 & -5.596 to 2.893 & 0.533 & -1.121 & -6.117 to 3.875 & 0.660 \\
\hline Unemployed & -5.227 & -23.279 to 12.825 & 0.570 & -1.966 & -6.775 to 2.843 & 0.423 & -.520 & -5.142 to 4.102 & 0.825 & -.724 & -6.165 to 4.716 & 0.794 \\
\hline Retired & -5.540 & -23.017 to 11.936 & 0.534 & -1.442 & -6.098 to 3.213 & 0.544 & -1.373 & -5.848 to 3.102 & 0.548 & -2.236 & -7.503 to 3.031 & 0.405 \\
\hline Not work & Reference & & & Reference & & & Reference & & & Reference & & \\
\hline \multicolumn{13}{|l|}{ Monthly income } \\
\hline 0 to $4 \mathrm{k}$ & -4.560 & -10.281 to 1.161 & 0.118 & .380 & -1.144 to 1.904 & 0.625 & .072 & -1.393 to 1.537 & 0.923 & -.210 & -1.934 to 1.515 & 0.812 \\
\hline 4,001 to $8 k$ & .439 & -4.127 to 5.004 & 0.851 & .352 & -.864 to 1.568 & 0.571 & .422 & -.747 to 1.591 & 0.479 & .438 & -.938 to 1.813 & 0.533 \\
\hline 8,001 to $12 \mathrm{k}$ & -1.109 & -6.059 to 3.841 & 0.661 & .266 & -1.053 to 1.584 & 0.693 & .493 & -.774 to 1.761 & 0.446 & .386 & -1.106 to 1.878 & 0.612 \\
\hline 12,001 to $16 \mathrm{k}$ & -2.261 & -7.286 to 6.202 & 0.418 & -765 & -.692 to 2.221 & 0.304 & .244 & -1.156 to 1.643 & 0.733 & .442 & -1.206 to 2.090 & 0.599 \\
\hline$>16 \mathrm{k}$ & -2.356 & -8.235 to 4.284 & 0.255 & -.047 & -1.844 to 1.749 & 0.959 & .332 & -1.395 to 2.059 & 0.707 & -.265 & -2.298 to 1.768 & 0.798 \\
\hline Not work & Reference & & & Reference & & & Reference & & & Reference & & \\
\hline \multicolumn{13}{|l|}{ Risk of loss job } \\
\hline Yes & 5.588 & -9.853 to 21.030 & 0.478 & 2.219 & -1.985 to 6.242 & 0.310 & -.912 & -4.855 to 3.030 & 0.650 & 1.691 & -2.963 to 6.345 & 0.476 \\
\hline No & -3.107 & -18.360 to 12.145 & 0.690 & .288 & -3.775 to 4.352 & 0.889 & -.993 & -4.896 to 2.910 & 0.618 & -.218 & -4.815 to 4.379 & 0.926 \\
\hline Not work & Reference & & & Reference & & & Reference & & & Reference & & \\
\hline \multicolumn{13}{|c|}{ Reduction in working days } \\
\hline Yes & 2.817 & -12.580 to 18.215 & 0.720 & .322 & -3.780 to 4.423 & 0.878 & 2.973 & -.981 to 6.927 & 0.141 & .707 & -3.933 to 5.348 & 0.765 \\
\hline No & .678 & -14.566 to 15.921 & 0.931 & -.469 & -4.530 to 3.591 & 0.821 & 1.227 & -2.678 to 5.133 & 0.538 & .376 & -4.218 to 4.970 & 0.873 \\
\hline Not work & Reference & & & Reference & & & Reference & & & Reference & & \\
\hline \multicolumn{13}{|c|}{ Monthly income reduction } \\
\hline Yes & -2.709 & -7.153 to 1.735 & 0.232 & -.452 & -1.636 to .732 & 0.454 & -1.069 & -2.207 to .068 & 0.065 & -1.008 & -2.348 to .331 & 0.140 \\
\hline No & -3.280 & -7.453 to .892 & 0.123 & -.499 & -1.495 to .728 & 0.499 & -.893 & -1.961 to .176 & 0.101 & -1.061 & -2.319 to .197 & 0.098 \\
\hline Not work & Reference & & & Reference & & & Reference & & & Reference & & \\
\hline
\end{tabular}

Abbreviation: $\beta$, beta coefficient; $\mathrm{CI}$, confidence interval 


\section{Physical Health Status, Psychological Distress, and Mental Health}

The results evidenced that $37.4 \%$ respondents rated their health as excellent, $43.01 \%$ as very good, $15.1 \%$ as good, $4.47 \%$ as regular, and $0.01 \%$ as bad. Around $2.8 \%$ of respondents had consulted a doctor in the clinic; $2.8 \%$ had been admitted to the hospital; $2 \%$ had been tested for COVID19 ; and $4.4 \%$ had been under quarantine by a health authority. However, clinic consultations, hospitalizations, being placed in obligatory quarantine, health status, and being tested for COVID-19 were not associated with DASS-21 and IES-R scores. Additionally, 54\% participants reported the presence of physical symptoms of COVID-19 during the past 14 days, most frequently headache $(48.71 \%)$, cough $(14.01 \%)$, coryza $(10.76 \%)$, and fever $(8.37 \%)$. Finally, the statistical analysis showed a significant association between the presence of physical symptoms with higher scores in the scales of the IES-R ( $B=6.609 ; 95 \% \mathrm{CI}=4.355$ to 8.863$)$ and the subscales of the DASS-21 (depression: $\mathrm{B}=1.805 ; 95 \% \mathrm{CI}=1.198$ to 2.412; anxiety: $\mathrm{B}=2.658 ; 95 \% \mathrm{CI}=2.090$ to 3.227 ; and stress $\mathrm{B}=2.688,95 \% \mathrm{CI}=2.025$ to 3.352 ) (see Table 4 ).

\section{Contact History, Psychological Distress, and Mental Health}

Overall, $2.7 \%$ of respondents had been in direct contact with an individual with confirmed COVID-19; 3.4\% showed indirect contact with an individual with confirmed COVID-19; and $8.1 \%$ reported indirect contact with an individual with confirmed COVID-19. Respondents with a history of direct contact with a confirmed case of COVID-19 showed a significant association with depression $(\mathrm{B}=2.168 ; 95 \% \mathrm{CI}=3.677$ to 4.330$)$, anxiety ( $\mathrm{B}=2.905 ; 95 \% \mathrm{CI}=1.111$ to 4.699$)$, and stress $(B=2.499 ; 95 \% C I=0.414$ to 4.584$)$. Finally, persons who had indirect contact with an individual with confirmed COVID-19 evidenced a significant association with anxiety $(\mathrm{B}=2.198 ; 95 \% \mathrm{CI}=0.582$ to 7.103$)$. The contact history of COVID-19 was not associated with IES-R scores (see Table 5).

\section{Knowledge and Concerns, Psychological Distress, and Mental Health}

A large number of the respondents knew the means of transmission of COVID-19 (94.5\%); however, 49.5\% lacked confidence related to the security of COVID-19 test. The majority of respondents $(51.7 \%)$ were very satisfied or satisfied with the amount of health information available on COVID-19, 35.5\% participants were just satisfied, and $13.8 \%$ were not satisfied. In addition, $35.4 \%$ of respondents were very satisfied or satisfied with the amount of information that the government provided regarding new cases and treatments tendency about COVID19 , and $64.6 \%$ considered their level of satisfied was regular or no satisfied. The main sources of information about COVID19 were social networks (Facebook/Twitter, 34.8\%), television (27.9\%), and scientific journals (15.2\%).
Knowledge about transmission was significantly associated with higher scores in DASS-21 subscales (depression: $\mathrm{B}=-2.058 ; 95 \% \mathrm{CI}=-3.373$ to -.743 ; anxiety: $\mathrm{B}=-2.546$; $95 \% \mathrm{CI}=-3.811$ to 1.281 ; and stress: $\mathrm{B}=-1.847 ; 95 \%$ $\mathrm{CI}=-3.307$ to -0.388$)$ and IES-R scale $(\mathrm{B}=-5.439 ; 95 \%$ $\mathrm{CI}=-10.342$ to -.536$)$. Similarly, lack confidence related to security on COVID-19 test was significantly associated with higher scores in DASS-21 subscales (depression: $\mathrm{B}=-1.027$; $95 \% \mathrm{CI}=-1.658$ to -0.396 ; and stress: $\mathrm{B}=-1.029 ; 95 \%$ $\mathrm{CI}=-1.730$ to -0.329$)$ and IES-R scale $(\mathrm{B}=-2.588 ; 95 \%$ $\mathrm{CI}=-4.930$ to -0.247$)$.

Satisfaction level about the amount of health information available about COVID-19 was significantly associated with higher scores in DASS-21 depression subscale. No associations were found between the satisfaction about the amount health information and IES-R scores. Finally, the level of satisfaction about amount information that the government provided regarding new cases and treatments of COVID-19 was significantly associated both higher scores in DASS-21 (anxiety and stress subscale) and IES-R scale. Social network, as the main source of information about COVID-19, was significantly associated with a higher IES-R scale score $(B=3.419 ; 95 \%$ $\mathrm{CI}=0.613$ to 6.226 ) (see Table 6).

\section{Precautionary Measures, Psychological Distress, and Mental Health}

The main precautionary measures about COVID-19 were hand washing behavior (35.74\%), home confinement $(28.77 \%)$, and avoid handshake (16.10\%). Statistical analysis showed that washing hands was significantly associated with higher scores in the IES-R $(B=0.49 ; 95 \% \mathrm{CI}=0.86$ to $0.015)$, and the DASS stress $(B=0.125 ; 95 \% \mathrm{CI}=0.52$ to 0.09 ), anxiety ( $B=0.82 ; 95 \% C I=0.65$ to 0.21$)$, and depression subscales $(B=0.45 ; 95 \% C I=0.8$ to 0.17$)$. Similarly, wearing masks was significantly associated with higher lower IES-R scores $(B=0.63 ; 95 \% C I=0.07$ to 1.12$)$ and lower scores in the DASS anxiety $(B=0.54 ; 95 \% \mathrm{CI}=0.74$ to $0.08)$ and depression subscales $(B=0.41 ; 95 \% \mathrm{CI}=0.71$ to $0.09)$. The majority of participants spent $>17 \mathrm{~h} / \mathrm{d}$ at home $(66.2 \%)$. Regarding assessment with the IES-R, respondents that stay at home $>9$ h showed a significant association with higher scores in the scale IES-R and the DASS-2 depression subscale (see Table 7).

\section{DISCUSSION}

This study examined the psychological distress of COVID-19 in a Mexican sample, just $1 \mathrm{wk}$ after a national health emergency was declared in Mexico. To our knowledge, this study is the first to evaluate psychological distress in a Mexican sample. Our findings showed that $50.3 \%$ of respondents rated the psychological distress of the outbreak as moderate to severe; $15.7 \%$ of respondents reported moderate to severe depressive symptoms; $22.6 \%$ of respondents reported moderate to severe 
TABLE 4

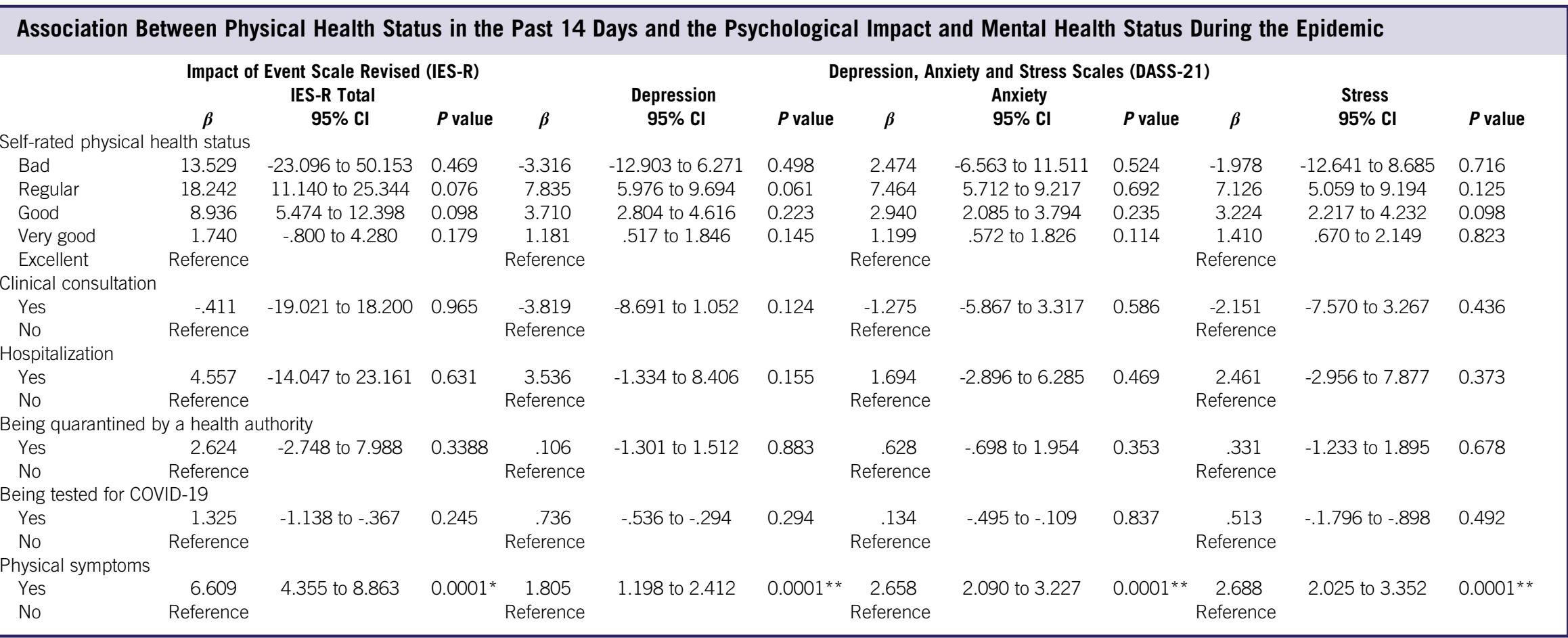

Abbreviations: $\beta$, beta coefficient; CI, confidence interval.

$* P<0.05$

$* * P<0.001$ 




anxiety symptoms; and $19.8 \%$ reported moderate to severe stress levels. The prevalence of moderate or severe psychological distress as measured by IES-R was higher than the prevalence of depression, anxiety, and stress as measured by the DASS-21. The differences in the results obtained between IES-R and DASS-21 may be due to the fact that the IES-R assesses psychological distress after a specific event. Therefore, respondents might refer the COVID-19 outbreak as the event, while the DASS-21 did not specify any such event, as previously reported. ${ }^{20}$

According to similar epidemics and pandemics, in such cases, serious concerns, such as fear of death can arise, and feelings of loneliness and anger can develop among people who are quarantined. ${ }^{26}$ In addition, people who are quarantined lose face-to-face connections and traditional social interventions, and this is a stressful phenomenon. ${ }^{27}$ Therefore, at these points, it was not surprising to find that the Mexican sample showed severe psychological distress during the COVID-19 outbreak, similarly with the findings originating from China, ${ }^{20,28}$ Canada, ${ }^{29}$ Iran, ${ }^{27}$ Japan, ${ }^{30}$ and Singapore. ${ }^{31}$

In support, it is recognized that widespread outbreaks of infectious diseases, such as SARS, ${ }^{32} \mathrm{H} 1 \mathrm{~N} 1,{ }^{33}$ and actually, COVID19 , are associated with psychological distress and symptoms of mental illness. ${ }^{34}$ Both psychologists, psychiatrists, and the health care system at large should be aware of these manifestations to subsequently implement early psychological interventions according the needs of specific populations.

Our findings suggest that females suffered greater psychological distress of the outbreak as well as higher levels of stress, anxiety, and depression. This finding corresponds to previous studies which found that women were at higher risk of depression, ${ }^{35,36}$ anxiety, ${ }^{37}$ and stress. ${ }^{38}$ It is likely that genetic, biological, chemical, hormonal, environmental, psychological, and social factors all intersect to contribute to mental disorders in women. ${ }^{39}$ In addition, we found that with older age, participants showed greater stress and had a greater psychological distress of COVID-19 outbreak. Young, middle-aged, and older adults may have di囚erent levels of exposure to school-related, work-related, and health-related stressors because of their life stages and associated life events. ${ }^{40}$ In addition, the Mexico government has shut down schools at all levels indefinitely. Currently, teachers are using online platforms to deliver lectures or other teaching activities. However, the uncertainty and potential negative distress on academic progression could have an adverse effect on the mental health of young people.

We found that divorced status had a greater likelihood of depression during the epidemic; in support, prior findings showing that the end of marriage through divorce is associated with a significant increase in the probability of a future depressive episode. ${ }^{41}$ Participants who live with 1 other person exhibited greater anxiety and greater psychological distress of the COVID-19 outbreak. This finding corresponds to 
TABLE 6

Association Between Knowledge and Concerns About the COVID-19 Outbreak and the Psychological Impact and Mental Health Status

\begin{tabular}{|c|c|c|c|c|c|c|c|c|c|c|c|c|}
\hline & \multirow{2}{*}{\multicolumn{3}{|c|}{$\begin{array}{l}\text { Impact of Event Scale Revised (IES-R) } \\
\text { IES-R Total }\end{array}$}} & \multicolumn{9}{|c|}{ Depression, Anxiety and Stress Scales (DASS-21) } \\
\hline & & & & & Depression & & & Anxiety & & & Stress & \\
\hline & $\beta$ & $95 \% \mathrm{CI}$ & $P$ value & $\beta$ & $95 \% \mathrm{Cl}$ & $P$ value & $\beta$ & $95 \% \mathrm{CI}$ & $P$ value & $\beta$ & $95 \% \mathrm{Cl}$ & $P$ value \\
\hline \multicolumn{13}{|c|}{ Knowledge about ways of transmission } \\
\hline Yes & -5.439 & -10.342 to -.536 & $0.030^{*}$ & -2.058 & -3.373 to -.743 & $0.002^{*}$ & -2.546 & -3.811 to 1.281 & $0.0001^{* *}$ & -1.847 & -3.307 to -.388 & $0.013^{*}$ \\
\hline Not & Reference & & & Reference & & & Reference & & & Reference & & \\
\hline \multicolumn{13}{|c|}{ Confidence in diagnosis COVID-19 } \\
\hline $\begin{array}{l}\text { Yes } \\
\text { No }\end{array}$ & -2.588 & -4.930 to -.247 & $0.030^{*}$ & -1.027 & -1.658 to -.396 & $0.0001^{* *}$ & -.496 & -1.104 to .11 & 0.109 & -1.029 & -1.730 to -.329 & $0.004^{*}$ \\
\hline \multicolumn{13}{|c|}{ Level of satisfaction of health information } \\
\hline No satisfaction & 2.216 & -4.939 to 9.371 & 0.544 & 2.766 & .830 to 4.702 & $0.0001^{* *}$ & 1.679 & -.182 to 3.541 & 0.077 & 1.294 & -.854 to 3.442 & 0.238 \\
\hline Poor satisfaction & -1.652 & -7.120 to 3.815 & 0.554 & 2.153 & .676 to 3.630 & $0.005^{*}$ & 1.385 & -.036 to 2.805 & 0.056 & 1.549 & -.099 to 3.178 & 0.066 \\
\hline Neutral & .366 & -3.717 to 4.449 & 0.861 & 1.241 & .138 to 2.345 & $0.027^{*}$ & 1.001 & -.060 to 2.062 & 0.065 & 1.063 & -. 162 to 2.287 & 0.089 \\
\hline Satisfied & -.764 & -4.762 to 3.125 & 0.700 & .895 & -.154 to 1.944 & 0.094 & .352 & -.657 to 1.360 & 0.495 & .752 & -.412 to 1.915 & 0.206 \\
\hline Very satisfied & Reference & & & Reference & & & Reference & & & Reference & & \\
\hline \multicolumn{13}{|c|}{ Level of satisfaction of information about the trend of new cases and potential treatment for COVID-19 } \\
\hline No satisfaction & 11.120 & 5.212 to 17.028 & $0.0001^{* *}$ & 1.092 & -.505 to 2.689 & 0.180 & 1.628 & .092 to 3.163 & $0.038^{*}$ & 2.881 & 1.109 to 4.653 & $0.0001^{* *}$ \\
\hline Poor satisfaction & 7.687 & 2.442 to 12.931 & $0.004^{*}$ & .988 & -.424 to 2.400 & 0.170 & 1.617 & .259 to 2.975 & $0.020^{*}$ & 1.978 & .411 to 3.545 & $0.013^{*}$ \\
\hline Neutral & 8.068 & 3.521 to 12.615 & $0.0001^{* *}$ & 1.047 & -.182 to 2.276 & 0.095 & 1.092 & -.090 to 2.274 & 0.070 & 1.731 & .367 to 3.095 & $0.013^{*}$ \\
\hline Satisfied & 4.826 & .256 to 9.396 & $0.038^{*}$ & .357 & -.879 to 1.593 & 0.572 & .760 & -.429 to 1.949 & 0.210 & 1.158 & -.214 to 2.529 & 0.098 \\
\hline Very satisfied & Reference & & & Reference & & & Reference & & & Reference & & \\
\hline \multicolumn{13}{|l|}{ Main source of information } \\
\hline Social networks & 3.419 & .613 to 6.225 & $0.017^{*}$ & 1.092 & -.505 to 2.689 & 0.180 & 1.628 & .092 to 3.163 & 0.038 & 2.881 & 1.109 to 4.653 & 0.142 \\
\hline Parents and friends & 3.744 & -3.502 to 10.989 & 0.311 & .988 & -.424 to 2.400 & 0.170 & 1.617 & .259 to 2.975 & 0.087 & 1.978 & .411 to 3.545 & 0.253 \\
\hline Internet & 28.249 & -8.189 to 64.688 & 0.129 & 1.047 & -.182 to 2.276 & 0.095 & 1.092 & -.090 to 2.274 & 0.070 & 1.731 & .367 to 3.095 & 0.472 \\
\hline Newspaper and magazines & .932 & -3.211 to 5.076 & 0.659 & .357 & -.879 to 1.593 & 0.572 & .760 & -.429 to 1.949 & 0.210 & 1.158 & -.214 to 2.529 & 0.098 \\
\hline $\begin{array}{l}\text { Scientific journals } \\
\text { Television }\end{array}$ & $\begin{array}{c}-6.542 \\
\text { Reference }\end{array}$ & -15.393 to 2.309 & 0.147 & $\begin{array}{l}-2.525 \\
\text { Reference }\end{array}$ & -.654 to 1.093 & 0.763 & $\begin{array}{c}.374 \\
\text { Reference }\end{array}$ & -.237 to 1.984 & 0.482 & 1.035 & -.353 to 1.948 & 0.948 \\
\hline
\end{tabular}

Abbreviations: $\beta$, beta coefficient; CI, confidence interval.

$* P<0.05$

$* * P<0.001$ 


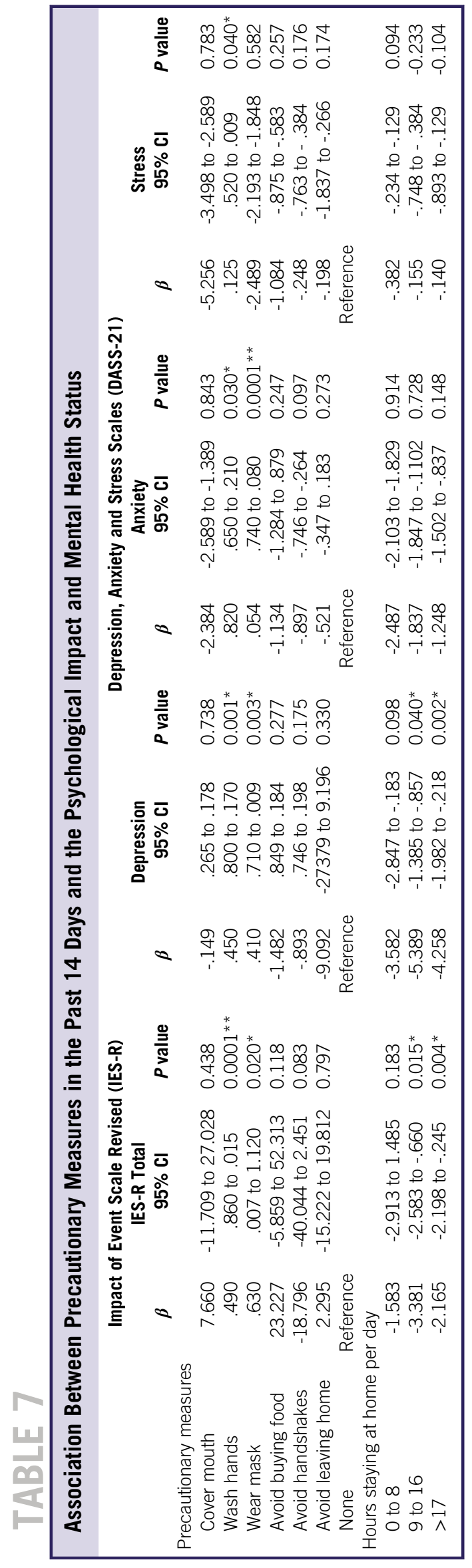

previously extensive epidemiological studies which found that family size predicts anxiety. ${ }^{42}$

On the other hand, it is necessary that the health authorities identify the immediate psychological needs of the general population presenting with physical symptoms during the epidemic. Our results revealed that the Mexican sample, which presented specific symptoms of COVID-19, experienced greater psychological distress on the outbreak and higher levels of stress, anxiety, and depression. Health professionals should take the opportunity to provide resources for psychological support and interventions for those who present with the above symptoms, especially during clinical consultations. Moreover, such interventions should also be guaranteed for infected individuals and their caregivers. ${ }^{20}$ Taking a family history is essential, and health professionals should enquire about the level of concern for other family members of contracting COVID-19, as these concerns are associated with altered mental status. In support, our results showed respondents had been in direct or indirect contact exhibited higher levels of anxiety, stress, and depression.

The goal of communication before and during a pandemic is to provide and exchange relevant information with the public, partners, and stakeholders to allow them to make wellinformed decisions and take appropriate actions to protect health and reduce the distress of rumors. ${ }^{43}$ In our study, lack of confidence in the COVID-19 test security and lower satisfaction with the health information received were associated with higher psychological distress of the outbreak and higher levels of stress, anxiety, and depression. Therefore, it is crucial to provide clear health information, with comprehensible messages and based on evidence to avoid adverse psychological reactions. $^{44}$

A major adverse consequence of the COVID-19 pandemic is likely to be increased social isolation and loneliness, which are strongly associated with anxiety, depression, self-harm, and suicide attempts across the lifespan. ${ }^{45}$ In our study, the majority of the participants that were homebound for $>9 \mathrm{~h} / \mathrm{d}$ during the epidemic suffered greater psychological distress from the outbreak as well as higher levels of depression. Under these conditions, the content of psychological interventions needs to be modified to suit the needs of the general population during the epidemic. Psychologists should produce and disseminate information materials on the psychological consequences of the quarantine and toll-free numbers should be activated to support all those who are confronted with psychological distress. ${ }^{46}$ For example, cognitive behavior therapy could be delivered online or by means of telephone to counteract depression in the home environment. For this reason, fine tuning effective psychological interventions is a future need, given that, after the public health emergency, a psychological distress emergency seems on the horizon.

Finally, our findings showed that specific precautionary measures as hand hygiene and wearing masks were associated with 
lower levels of psychological distress, depression, anxiety, and stress. Our finding is similar to a previous study, which suggests that the precautionary measures adopted to prevent the spread of COVID-19 could have had protective psychological effects during the early stage of the epidemic. ${ }^{20}$

This study has several limitations. First, due the time-sensitivity of the COVID-19 outbreak, we used the snowball sampling strategy; this strategy was not based on a random selection of the sample, and the study population did not reflect the actual pattern of the general population. Second, the sampling was carried out by students, leading to selection bias. Therefore, our conclusion was less generalizable to the entire population, particularly less-educated people. Last, the number of respondents with contact history and who had sought medical consultations was very small. As a result, our findings could not be generalized to confirmed or suspected cases of COVID-19.

Notwithstanding the above limitations, this study provides invaluable information on the psychological effects in the Mexican sample, 1 wk after the outbreak of COVID-19 was declared a national health emergency in Mexico. In addition, our results could be used as a historical reference and provide a baseline for evaluating prevention, control, and treatment efforts throughout the remainder of the COVID-19 epidemic.

\section{CONCLUSIONS}

Together, the data show that the COVID-19 outbreak results in considerable psychological distress among the Mexican sample examined. Public health officials, infectious diseases physicians, psychiatrists, psychologists, and the health care system at large need to be made aware of this issue.

\section{About the Authors}

School of Medicine, University of Colima, Colima, Mexico (Drs Cortés-Álvarez, Vuelvas-Olmos) and School of Medicine, José Martí University, Colima, México (Drs Cortés-Álvarez, Piñeiro-Lamas).

Correspondence and reprint requests to César Rubén Vuelvas-Olmos, PhD, Medical Sciences Program, School of Medicine, University of Colima, Av. Universidad 333 , Colima, Col.28040, Mexico (e-mail: cesar_vuelvas@ucol.mx)

\section{Acknowledgments}

The authors thank the medical students of the José Martí University for their valuable support.

\section{Conflict of Interest Statement}

The authors declare that they have no conflicts of interest.

\section{Supplementary material}

To view supplementary material for this article, please visit https://doi.org/10.1017/dmp.2020.215

\section{REFERENCES}

1. Mahase E. China coronavirus: WHO declares international emergency as death toll exceeds 200. BMJ. 2020;368:m408.

2. Secretaría de Gobernación. ACUERDO por el que se declara como emergencia sanitaria por causa de fuerza mayor, a la epidemia de enfermedad generada por el virus SARS-CoV2 (COVID-19). México. Published April 11, 2020. http://dof.gob.mx/nota_detalle.php?codigo=5590745\& fecha=30/03/2020. Accessed July 2, 2020.

3. SEGOB. ACUERDO por el que se establecen acciones extraordinarias para atender la emergencia sanitaria generada por el virus SARS-CoV2. Diario Oficial de la Federación. 2020. Published April 12, 2020. https://dof.gob.mx/nota_detalle.php?codigo=5590914\&fecha=31/03/2020. Accessed July 2, 2020.

4. Forbes Mexico. Coronavirus en México | Suben precios de cubrebocas y gel por compras de pánico. Published April 12, 2020. https://www.forbes. com.mx/coronavirus-en-mexico-suben-precios-de-cubrebocas-y-gel-porcompras-de-panico/?fbclid=IwAR1945T5hhuuGAUC2GElam-KoTg ZruCSituwf9NRjrQnQMrOKinwt132Rs. Accessed July 2, 2020.

5. Mexico News Daily. Oil price plunge into negative territory another blow to Pemex. 2020. Published May 21, 2020. https://mexiconewsdaily.com/ news/oil-price-plunges-into-negative-territory/?fbclid=IwAR2ozWJp71hr 3tKiobZjOjTy-bC3le7PUrEjg73h3pYZ41ESek9O4ET8n_E. Accessed July 2, 2020.

6. Villa y Caña P, Morales A. Por Covid-19, se han perdido 346 mil puestos de trabajo: STPS. El Universal. 2020. Published April 12, 2020. https:// www.eluniversal.com.mx/nacion/por-covid-19-se-han-perdido-346-milpuestos-de-trabajo-stps?fbclid=IwAR1h3L5vR24A0iisX_JmmfVwWSAm W2_CF3TttR9kWVWneGAB8z6NG9jXWh8. Accessed July 2, 2020.

7. Díaz-Bautista A. Unemployment estimates in Mexico, the United States and Canada are for more than 28 million during the 2020 Health and Economic Crisis. Beyond Borders Gazette. 2020. Published April 29, 2020. https://beyondbordersnews.com/2020/04/22/unemployment-estimatesin-mexico-the-united-states-and-canada-are-for-more-than-28-millionduring-the-2020-health-and-economic-crisis/. Accessed July 2, 2020.

8. Terrizzi JA, Shook NJ, McDaniel MA. The behavioral immune system and social conservatism: a meta-analysis. Evol Hum Behav. 2013;34(2): 99-108.

9. Mortensen CR, Becker DV, Ackerman JM, et al. Infection breeds reticence: the effects of disease salience on self-perceptions of personality and behavioral avoidance tendencies. Psychol Sci. 2010;21(3):440-447.

10. Schaller M, Murray DR. Pathogens, personality, and culture: disease prevalence predicts worldwide variability in sociosexuality, extraversion, and openness to experience. J Pers Soc Psychol. 2008;95(1):212-221.

11. Norris FH, Friedman MJ, Watson PJ. 60,000 disaster victims speak: Part II. Summary and implications of the disaster mental health research. Psychiatry. 2002;65(3):240-260.

12. Slovic P. Perception of risk. Science. 1987 ;236(4799):280-285.

13. Kiecolt-Glaser JK, McGuire L, Robles TF, et al. Emotions, morbidity, and mortality: new perspectives from psychoneuroimmunology. Annu Rev Psychol. 2002;53(1):83-107.

14. Chua SE, Cheung V, McAlonan GM, et al. Stress and psychological impact on SARS patients during the outbreak. Can J Psychiatry. 2004:49(6):385-390.

15. Tsang HWH, Scudds RJ, Chan EYL. Psychosocial Impact of SARS. Vol. 10, Emerging Infectious Diseases. Atlanta, GA: Centers for Disease Control and Prevention; 2004:1326-1327.

16. Wang $Y, X u B, Z$ hao $G$, et al. Is quarantine related to immediate negative psychological consequences during the 2009 H1N1 epidemic? Gen Hosp Psychiatry. 2011;33(1):75-77.

17. Taylor MR, Agho KE, Stevens GJ, et al. Factors influencing psychological distress during a disease epidemic: data from Australia's first outbreak of equine influenza. BMC Public Health. 2008;8:347.

18. Jacobs J, Taylor M, Agho K, et al. Factors associated with increased risk perception of pandemic influenza in Australia. Influenza Res Treat. 2010;2010:947906. 
19. Di Giuseppe G, Abbate R, Albano L, et al. A survey of knowledge, attitudes and practices towards avian influenza in an adult population of Italy. BMC Infect Dis. 2008;8:36.

20. Wang C, Pan R, Wan X, et al. Immediate psychological responses and associated factors during the initial stage of the 2019 coronavirus disease (COVID-19) epidemic among the general population in China. Int J Environ Res Public Health. 2020;17(5):1729.

21. Mojica SAM, Mendoza OM, Guadarrama RG, et al. Medición del Trastorno por Estrés Postraumático (TEPT) en universitarios Mexicanos. Salud Ment. 2013;36(6):493-503.

22. Tiemensma J, Depaoli S, Winter SD, et al. The performance of the IES-R for Latinos and non-Latinos: assessing measurement invariance. PLoS One. 2018;13(4):e0195229.

23. Wheaton MG, Abramowitz JS, Berman NC, et al. Psychological predictors of anxiety in response to the H1N1 (swine flu) pandemic. Cognit Ther Res. 2012;36(3):210-218.

24. McAlonan GM, Lee AM, Cheung V, et al. Immediate and sustained psychological impact of an emerging infectious disease outbreak on health care workers. Can J Psychiatry. 2007;52(4):241-247.

25. García-Rivera B, Maldonado-Radillo SE, Ramírez Barón M. Estados afectivos emocionales (depresión, ansiedad y estrés) en personal de enfermería del sector salud pública de México. Summa Psicológica. 2014;11(1):65-73.

26. Brooks SK, Webster RK, Smith LE, et al. The psychological impact of quarantine and how to reduce it: rapid review of the evidence. Lancet. 2020;395(10227):912-920.

27. Zandifar A, Badrfam R. Iranian mental health during the COVID-19 epidemic. Asian J Psychiatry. 2020;51:101990.

28. Dong L, Bouey J. Public mental health crisis during COVID-19 pandemic, China. Emerg Infect Dis. 2020;26(7):1616-1618.

29. Asmundson GJG, Taylor S. Coronaphobia: fear and the 2019-nCoV outbreak. J Anxiety Disord. 2020;70:102196.

30. Shigemura J, Ursano RJ, Morganstein JC, et al. Public responses to the novel 2019 coronavirus (2019-nCoV) in Japan: mental health consequences and target populations. Psychiatry Clin Neurosci. 2020;74(4): 281-282.

31. Ho CS, Chee CY, Ho RC. Mental Health strategies to combat the psychological impact of COVID-19 beyond paranoia and panic. Ann Acad Med Singapore. 2020;49(1):1-3.

32. Wu P, Fang Y, Guan Z, et al. The psychological impact of the SARS epidemic on hospital employees in China: exposure, risk perception, and altruistic acceptance of risk. Can J Psychiatry. 2009;54(5):302-311.
33. Matsuishi K, Kawazoe A, Imai H, et al. Psychological impact of the pandemic (H1N1) 2009 on general hospital workers in Kobe. Psychiatry Clin Neurosci. 2012;66(4):353-360.

34. Bao Y, Sun Y, Meng S, et al. 2019-nCoV epidemic: address mental health care to empower society. Lancet. 2020;395(10224):e37-e38.

35. Baxter AJ, Scott KM, Ferrari AJ, et al. Challenging the myth of an "epidemic" of common mental disorders: trends in the global prevalence of anxiety and depression between 1990 and 2010. Depress Anxiety. 2014;31(6):506-516.

36. Whiteford HA, Degenhardt L, Rehm J, et al. Global burden of disease attributable to mental and substance use disorders: findings from the Global Burden of Disease Study 2010. Lancet. 2013;382(9904): 1575-1586.

37. Jalnapurkar I, Allen M, Pigot T. Sex differences in anxiety disorders: a review. J Psychiatry Depress Anxiety. 2018;4(12):3-16.

38. Sandanger I, Nygård JF, Sørensen T, et al. Is women's mental health more susceptible than men's to the influence of surrounding stress? Soc Psychiatry Psychiatr Epidemiol. 2004;39(3):177-184.

39. Albert PR. Why is depression more prevalent in women? J Psychiatry Neurosci. 2015;40(4):219-221.

40. Chen Y, Peng Y, Xu H, et al. Age differences in stress and coping: problemfocused strategies mediate the relationship between age and positive affect. Int J Aging Hum Dev. 2018;86(4):347-363.

41. Sbarra DA, Emery RE, Beam CR, et al. Marital dissolution and major depression in midlife: a propensity score analysis. Clin Psychol Sci. 2014;2(3):249-257.

42. Grinde B, Tambs K. Effect of household size on mental problems in children: results from the Norwegian Mother and Child Cohort study. BMC Psychol. 2016;4(1):31.

43. World Health Organization. Pandemic influenza preparedness and response: a WHO guidance document. 2009. Published April 27, 2020. http://www.ncbi.nlm.nih.gov/books/NBK143062/. Accessed July 2, 2020.

44. Wray RJ, Becker SM, Henderson N, et al. Communicating with the public about emerging health threats: lessons from the pre-event message development project. Am J Public Health. 2008;98(12):2214-2222.

45. Holmes EA, O'connor RC, Perry H, et al. Paper multidisciplinary research priorities for the COVID-19 pandemic: a call for action for mental health science. Lancet Psychiatry. 2020;7(6):547-560.

46. Orrù $G$, Ciacchini R, Gemignani A, et al. Psychological intervention measures during the COVID-19 pandemic. Clin Neuropsychiatry. 2020;17(2): 76-79. 